\title{
Versatile Post-functionalisation Strategy for the Formation of Modular Organic-Inorganic Polyoxometalate Hybrids
}

\section{Introduction}

The synthesis of intricate hybrid organic-inorganic structures for the formation of new functional materials remains a major challenge. This problem can be addressed by exploiting wellknown building blocks with established catalytic, electronic, conductive, optical or biological properties, and combining them to form hybrid materials that will benefit from the synergy of their combined properties., ${ }^{1,2}$ Polyoxometalates (POMs), which are discrete anionic metal-oxygen nanoclusters of group 5 and 6 transition metals in their highest oxidation states, are promising inorganic building-blocks for the formation of such hybrid materials. ${ }^{3}$ This family of compounds includes a wide variety of structures such as (1) the Lindqvist structure with general formula $\left[\mathrm{M}_{6} \mathrm{O}_{19}\right]^{\mathrm{n}-},(2)$ the Anderson-Evans structure with general formula $\left[\left(\mathrm{X}^{\mathrm{n}}\right) \mathrm{M}_{6} \mathrm{O}_{24}\right]^{(6-n)-}$, and (3) the WellsDawson structure with general formula $\left[\mathrm{X}_{2} \mathrm{M}_{18} \mathrm{O}_{62}\right]^{\text {n- }}(\mathrm{M}$ is typically $\mathrm{Mo}^{6+}, \mathrm{W}^{6+}$ or $\mathrm{V}^{5+}$ depending on the structure; $\mathrm{X}$ is a heteroatom such as $\mathrm{P}, \mathrm{Cr}$, Al, etc.). POMs have many interesting physical and chemical properties due to their tuneable size,

\footnotetext{
a. Laboratory for Bioinorganic Chemistry, KU Leuven Department of Chemistry, Celestijnenlaan 200F, 3001 Leuven, Belgium. E-mail: tatjana.vogt@kuleuven.be b. Biomolecular Architecture, KU Leuven Department of Chemistry, Celestijnenlaan 200F, 3001 Leuven, Belgium

c. Department of Chemistry, Ludwig-Maximilian-University, Butenandtstr. 5-13, Haus D, 81377 Munich, Germany
}

charge density, acidity, and redox potential. As a result, they have been extensively investigated for applications in many fields such as catalysis, energy storage, materials science, supramolecular chemistry and medicine. ${ }^{4-9}$ Moreover, some archetypal POM structures can be functionalised with organic ligands to form organic-inorganic hybrid polyoxometalates (HPOMs), further expanding their physical and chemical properties. ${ }^{10-12}$

POMs covalently functionalised with triols $\left.\left(\left(\mathrm{HOCH}_{2}\right)_{3} \mathrm{C}-\mathrm{R}\right)\right)$, in which three of the bridging oxo ligands are replaced by the triol, are one of the most important classes of HPOMs. ${ }^{12,13}$ Whether a POM can be functionalised with triol ligands and how many triols can be attached, highly depends on the POM structure. The Lindqvist hexavanadate structure $\left(V_{6}\right)$ is typically bis-functionalised (Figure 1(a)) unless it is reduced, ${ }^{14}$ while the Anderson-Evans structure $\left(\mathrm{XM}_{6}\right)$ can be either mono- or bisfunctionalised depending on the nature of the heteroatom present at its centre (Figure $\mathbf{1}(\mathbf{b}-\mathbf{c})$ ). ${ }^{15}$ On the other hand, the vanadium trisubstituted Wells-Dawson structure $\left(\mathrm{P}_{2} \mathrm{~V}_{3} \mathrm{~W}_{15}\right)$ can only be mono-functionalised (Figure $\mathbf{1}(\mathbf{d})$ ). ${ }^{16}$ All these HPOM structures are highly versatile since they can be easily postfunctionalised with a wide variety of organic moities. ${ }^{17-20}$ However, the use of polyols for the functionalisation of POMs with other species aside from organic molecules - such as functional surfaces, ${ }^{21-24}$ nanoparticles ${ }^{25,26}$ and even other POMs - is challenging and remains scarcely explored. 


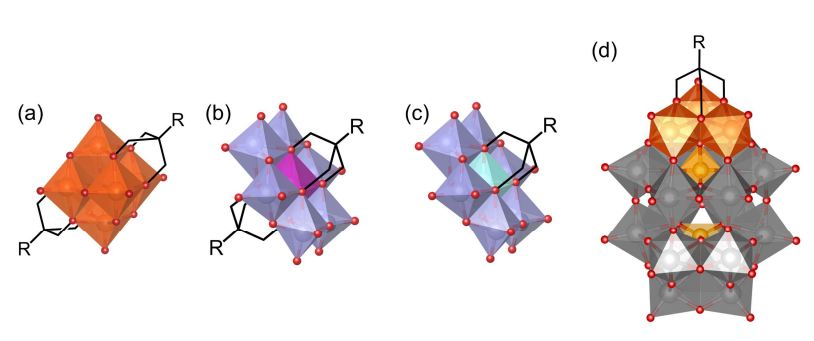

Figure 1 Representations of different hybrid polyoxometalate (HPOM) structures: (a) the bis-functionalised $\left[\mathrm{V}_{6} \mathrm{O}_{13}\left\{\left(\mathrm{OCH}_{2}\right)_{3} \mathrm{C}-\mathrm{R}\right\}_{2}\right]^{2-}$ Lindqvist hexavanadate, (b) the bisfunctionalised $\delta-\left[\left\{X^{n+}\right\} \mathrm{M}_{6} \mathrm{O}_{18}\left\{\left(\mathrm{OCH}_{2}\right)_{3} \mathrm{C}-\mathrm{R}\right\}_{2}\right]^{(6-n)}$ and (c) mono-functionalised $\delta$ $\left.\left[\left\{\mathrm{X}^{\mathrm{n}+}\right\}(\mathrm{OH})_{3} \mathrm{M}_{6} \mathrm{O}_{18}\left(\mathrm{OCH}_{2}\right)_{3} \mathrm{C}-\mathrm{R}\right\}\right]^{(6-\mathrm{n})}$ - Anderson-Evans as well as (d) the mono-functionalised $\left[\mathrm{P}_{2} \mathrm{~V}_{3} \mathrm{~W}_{15} \mathrm{O}_{59}\left\{\left(\mathrm{OCH}_{2}\right)_{3} \mathrm{C}-\mathrm{R}\right\}\right]^{6-}$ vanadium trisubstituted Wells-Dawson. Oxygen in red, vanadium in orange, metal addenda atom (Mo or W) in purple or grey, phosphorous in yellow, heteroatom $\mathrm{X}$ in magenta or cyan and organic carbon chain in skeletal form in black.

To date, only a few examples of POM structures connected together to form POM-POM hybrids have been reported. In general, POM-POM hybrid structures have been obtained via self-assembly of POMs functionalised with pyridyl ligands promoted by metal ion coordination or via covalent attachment employing an organic linker to form more robust POM-POM hybrids. ${ }^{27,28}$ The latter can be achieved through two main strategies. The first approach is based on triol functionalisation using polyol ligands, while the second uses the replacement of some of the terminal oxo ligands of the POM by a nitrogen atom on the linker to form an organoimido POM derivative. The method employing polyols has been mostly reported for linking together $\mathrm{P}_{2} \mathrm{~V}_{3} \mathrm{~W}_{15}$ POMs to form POM-POM "dumbbell", "triangular" and "dendritic" hybrids, which are catalytically active or can self-assemble to form vesicles, a process that can be controlled by coordination of metal ions depending on the nature of the organic linker. ${ }^{29-33}$ Linking $\mathrm{XM}_{6}$ POMs with polyol ligands has also been used to form both "dumbbell" and polymeric structures. ${ }^{34,35} \quad$ Similarly, 1,3,5benzenetricarboxamide ligands with three triol groups have been used to form extended networks of $\mathrm{V}_{6}$ POMs, which showed promising catalytic activity. ${ }^{36}$ On the other hand, the second method of covalent attachment of POM structures based on organoimido POM derivatives involves linking Lindqvist hexamolybdate $\left(\mathrm{Mo}_{6}\right)$ POM structures to form "dumbbell" hybrids with the same $\mathrm{Mo}_{6}$ POMs at either end of an organic linker. ${ }^{37,38}$ Furthermore, nanorod triads, in which POMs bis-functionalised with tris(hydroxymethyl)aminomethane $\left(\left(\mathrm{HOCH}_{2}\right)_{3} \mathrm{CNH}_{2}\right)$ were used as the linker between two $\mathrm{Mo}_{6}$, have also been reported and displayed redox activity and photochromism. ${ }^{39-41}$ However, the formation of POM-POM hybrids using this approach is currently mostly limited to hexamolybdates and requires more complex reaction conditions involving the use of additional reagents, such as $\mathrm{N}, \mathrm{N}^{\prime}$-dicyclohexylcarbodiimide (DCC). ${ }^{42}$ On the other hand, the formation of triol-functionalised HPOMs can be achieved for a much wider range of POM structure types via a simpler one-pot synthesis involving just mixing of the starting materials under reflux. Nevertheless, the use of polyols to link
POMs together has so far been mainly limited to the formation of hybrid structures involving only one kind of POM.

A very limited number of discrete structures that contain more than one type of POM have been reported even though combining different structural types of POMs in one molecule could result in interesting catalytic, redox, electronic, and magnetic properties, as these are highly dependent on the structure and composition of the POMs. Such POM-POM hybrids would not only benefit from the synergistic contributions of the organic and inorganic components but also from the association of different inorganic species. This can be seen from a recently reported $2 \mathrm{D}$ hybrid containing $\left[\mathrm{V}_{10} \mathrm{O}_{28}\right]^{6-}$ and $\left[\mathrm{XV}_{12} \mathrm{O}_{38}\right]^{12-}\left(\mathrm{X}=\mathrm{Ni}^{4+}, \mathrm{Mn}^{4+}\right)$ POMs non-covalently linked by $4,4^{\prime}$-bipyridine- $N, N^{\prime}$-dioxide and lanthanide ions to form a novel extended structure which displayed better catalytic activity than the individual POMs. ${ }^{43}$ However, the reported synthetic approach has a limited general applicability and offers restricted versatility and control over the resulting mixed POM hybrids. Consequently, the formation of molecular hybrids containing more than one type of metal-oxo cluster presents a synthetic challenge, and to the best of our knowledge a general strategy for combing different metal-oxo structure types into a discrete hybrid structure has not been reported so far. Therefore, since an accessible post-functionalisation strategy for the combination of different types of metal-oxo clusters would be a valuable asset in the directed formation of novel functional materials, in this paper we propose a novel approach based on the controlled design and combination of POM building-blocks with polyols resulting in the formation of mixed heterometallic POM-POM hybrids.

\section{Results and discussion}

Herein, we report the synthesis and characterisation of the tetrabutylammonium (TBA) and sodium salts of two novel Lindqvist and Anderson-Evans HPOMs bis-functionalised with dipentaerythritol $\left(\left(\mathrm{HOCH}_{2}\right)_{3} \mathrm{CCH}_{2} \mathrm{OCH}_{2}\left(\mathrm{CH}_{2} \mathrm{OH}\right)_{3} ; \quad\right.$ (dP): $\left[\mathrm{V}_{6} \mathrm{O}_{13}\left\{\left(\mathrm{OCH}_{2}\right)_{3} \mathrm{CCH}_{2} \mathrm{OCH}_{2} \mathrm{C}\left(\mathrm{CH}_{2} \mathrm{OH}\right)_{3}\right\}_{2}\right]^{2-} \quad$ (L) and $\left[\mathrm{CrMo}_{6} \mathrm{O}_{18}\left\{\left(\mathrm{OCH}_{2}\right)_{3} \mathrm{CCH}_{2} \mathrm{OCH}_{2} \mathrm{C}\left(\mathrm{CH}_{2} \mathrm{OH}\right)_{3}\right\}_{2}\right]^{3-}$ (C). These novel symmetrical HPOMs, functionalised on either side of the POM core $\left(P O M_{1}\right)$ with a ligand containing free triol groups $(R)$, can be used as building blocks for coupling different types of POM structures $\left(\mathrm{POM}_{2}\right)$ to form $\mathrm{POM}_{2}-\mathrm{R}-\mathrm{POM}_{1}-\mathrm{R}-\mathrm{POM}_{2}$ hybrids. One key requirement for the successful formation of such a POMPOM hybrid structure is the presence of anchoring points on the second POM onto which the free triol "claws" can be grafted during a POM post-functionalisation reaction. Therefore, for this purpose, the vanadium trisubstituted Wells-Dawson $\left(\left[\mathrm{P}_{2} \mathrm{~V}_{3} \mathrm{~W}_{15} \mathrm{O}_{62}\right]^{9-;}\right.$ D) and the aluminium Anderson-Evans $\left(\left[\mathrm{Al}(\mathrm{OH})_{6} \mathrm{Mo}_{6} \mathrm{O}_{18}\right]^{3-;}\right.$ A) POM structures were selected since D can be mono-functionalised with triols through the $\mathrm{V}_{3}$ cap, ${ }^{16}$ while mono-functionalisation of $\mathbf{A}$ can be achieved by attachment of the triol on one side of the central $\left\{\mathrm{AlO}_{6}\right\}$ octahedron. ${ }^{15,35}$ Upon binding of the triol ligand to one side of the $\mathrm{AlMo}_{6}$ core, the $\mathrm{OH}$ groups on the other side of the core become less labile, thus preventing further functionalisation that would result in the formation of infinite chains: (-R-POM ${ }^{-}$ 


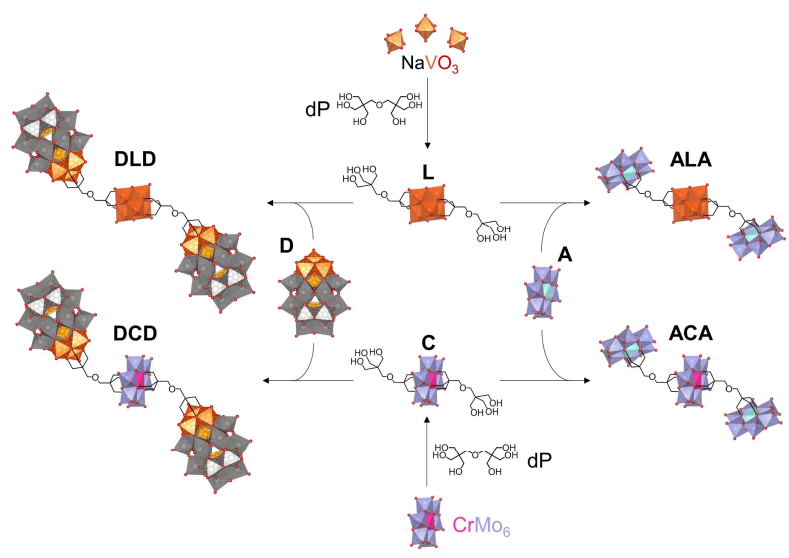

Figure 2 Reaction scheme showing the formation of $\left[\mathrm{V}_{6} \mathrm{O}_{13}\left\{\left(\mathrm{OCH}_{2}\right)_{3} \mathrm{C}-\mathrm{R}\right\}_{2}\right]^{2-}$ (L) and $\left[\mathrm{CrMo}_{6} \mathrm{O}_{18}\left\{\left(\mathrm{OCH}_{2}\right)_{3} \mathrm{C}-\mathrm{R}\right\}_{2}\right]^{3-}$ (C) functionalised with dipentaerythritol $(\mathrm{R}=$ $\left.\mathrm{CH}_{2} \mathrm{OCH}_{2} \mathrm{C}\left(\mathrm{CH}_{2} \mathrm{OH}\right)_{3}\right)$ as building blocks for the formation of 4 heterogeneous POM-POM hybrids via post-functionalisation with $\left[\mathrm{P}_{2} \mathrm{~V}_{3} \mathrm{~W}_{15} \mathrm{O}_{62}\right]^{9-}(\mathrm{D})$ or $\left[\mathrm{Al}(\mathrm{OH})_{6} \mathrm{Mo}_{6} \mathrm{O}_{18}\right]^{3-}(\mathrm{A}): \mathrm{DLD}$, DCD, ALA, ACA.

R-POM -$)_{n} \cdot{ }^{35}$ Hence, the ability of dP-functionalised POMs to form discrete novel structures by covalently connecting POMs with different compositions and properties was established by post-functionalising $\mathbf{L}$ and $\mathbf{C}$ with $\mathbf{D}$ or $\mathbf{A}$ as shown in Figure $\mathbf{2}$.

\section{Synthesis \& characterisation of bis-dipentaerythritol HPOMs}

The formation of the dP-functionalised building-blocks, C and L, was achieved by heating the POM precursors (i.e. $\left[\mathrm{Cr}(\mathrm{OH})_{6} \mathrm{Mo}_{6} \mathrm{O}_{18}\right]^{3-}\left\{\mathrm{CrMo}_{6}\right\}$ or metavanadate) with $\mathrm{dP}$ in aqueous solution. Then, the desired TBA-salts were obtained by precipitation with tetrabutylammonium bromide. The successful synthesis of $\mathbf{L}$ through the attachment of only one of the triol groups of each dP ligand to either side of the $\mathrm{V}_{6} \mathrm{POM}$ core, thereby breaking the symmetry of $\mathrm{dP}$, was unambiguously confirmed by ${ }^{1} \mathrm{H}$ and ${ }^{13} \mathrm{C}$ NMR (Figure S4-S5). In the ${ }^{1} \mathrm{H}$ NMR spectrum, the $\mathrm{V}-\mathrm{O}-\mathrm{CH}_{2}$ - protons attached to the $\mathrm{POM}$ are highly deshielded, giving rise to a peak at $5.04 \mathrm{ppm}$, while a peak at $3.46 \mathrm{ppm}$ was observed for the free $-\mathrm{CH}_{2}-\mathrm{OH}$ ethyl protons as expected for POM-bound and free $-\mathrm{OCH}_{2}$ - groups. ${ }^{44,45}$ Similarly, the peak due to the bridging $-\mathrm{CH}_{2}-\mathrm{O}-\mathrm{CH}_{2}$ - ether group was split into two peaks at 3.31 and $3.29 \mathrm{ppm}$ due to the formation of the functionalised POM. The ${ }^{13} \mathrm{C}$ NMR spectrum showed a similar break in the symmetry of $\mathrm{dP}$, with peaks at 85.94 and $63.10 \mathrm{ppm}$ assigned to the $\mathrm{V}-\mathrm{O}-\mathrm{CH}_{2}-$ and $-\mathrm{CH}_{2}-\mathrm{OH}$ carbons respectively, and two peaks observed at 73.21 and $71.79 \mathrm{ppm}$ corresponding to the $-\mathrm{CH}_{2}-\mathrm{O}-\mathrm{CH}_{2}$ - carbons. The formation of the $\mathrm{V}_{6}$ POM core was also confirmed by the presence of a single sharp peak at $-497 \mathrm{ppm}$ in the ${ }^{51} \mathrm{~V}$ NMR spectrum (Figure S6), which is typical of trans-functionalised hexavanadates, ${ }^{45,46}$ as well as by the characteristic peaks in the IR spectrum (Figure S10) at 953 ( $v$ V = O, vs), 810 ( $v$ V-O-V, s), 791 ( $v$ V-O-V, s), and 709 (v V-O-V, vs) $\mathrm{cm}^{-1} .47$

Due to the paramagnetic nature of $\mathrm{Cr}^{3+}, \mathrm{C}$ could not be fully characterised by ${ }^{1} \mathrm{H}$ NMR as very broad peaks were obtained (Figure S8). ${ }^{34}$ Similarly, in the ${ }^{13} \mathrm{C}$ NMR spectrum only three peaks corresponding to carbon environments furthest away from the $\mathrm{Cr}^{3+}$ could be observed, with the peaks becoming weaker and broader with increasing proximity to the POM (Figure 59). Nevertheless, the integrity of the POM core was confirmed from the characteristic peaks in the IR spectrum (Figure S12) at $937(v \mathrm{Mo}=\mathrm{O}, \mathrm{s}), 912(\mathrm{v} \mathrm{Mo}=\mathrm{O}, \mathrm{s}), 897$ ( $v \mathrm{Mo}=\mathrm{O}$, s) and 650 ( $v$ Mo-O-Mo, vs) $\mathrm{cm}^{-1} .{ }^{48,49}$ Furthermore, the peaks at 1130 and $1016 \mathrm{~cm}^{-1}$ due to $\mathrm{C}-\mathrm{O}$ stretching vibrations are indicative of attachment of the tripodal anchor of $\mathrm{dP}$ onto the POM core, while the peaks in the region $400-600 \mathrm{~cm}^{-1}$ are characteristic of a bis-functionalised $\mathrm{CrMo}_{6}$ and can be distinguished from the all-inorganic POM as well as from the mono-functionalised form. ${ }^{50,51}$ In addition, the $\mathrm{CrMo}_{6} \mathrm{POM}$ core gives rise to characteristic peaks in the UV-Vis absorbance spectrum (Figure S13) at $214 \mathrm{~nm}\left(\varepsilon=5.77 \times 10^{5} \mathrm{M}^{-1} \mathrm{~cm}^{-1}\right)$ and 512 $\mathrm{nm}\left(\varepsilon=8.96 \mathrm{M}^{-1} \mathrm{~cm}^{-1}\right)$, which are due to the ligand to metal charge transfer (LMCT) from the ligand-centred $\mu_{3}-\mathrm{OR} \pi$ orbitals to the metal-centred $\mathrm{Mo}^{6+} \mathrm{t}_{2 \mathrm{~g}}$ orbitals $\left(\mathrm{O} \rightarrow \mathrm{Mo}^{6+}\right)$ and the $\mathrm{d}-\mathrm{d}$ transition from the HOMO $t_{2 g}$ to the LUMO $e_{g}$ of $\mathrm{Cr}^{3+}$ respectively. Furthermore, functionalisation of the POM clearly results in a hypochromic shift in the absorbance bands with respect to those of the all-inorganic $\mathrm{CrMo}_{6}$ precursor, which gives peaks at $239 \mathrm{~nm}$ and $540 \mathrm{~nm}$, as has been previously reported for mono-functionalised $\mathrm{CrMo}_{6}$ species. ${ }^{51,52}$

Moreover, the composition of the pure compound for both $\mathbf{L}$ and $\mathbf{C}$ was further confirmed by elemental analysis, negative mode ESI-MS (Figure S3 \& S7) and single crystal X-ray diffraction. Single crystals were obtained by ether diffusion into acetonitrile/methanol or ethanol solutions of $\mathbf{L}$ and $\mathbf{C}$ respectively. Both compounds crystallised forming a hydrogen bonding network in the centrosymmetric $P 2_{1} / c$ space group and display the expected bis-functionalised Lindqvist and AndersonEvans structures (Figure $\mathbf{3}$ ). The crystal structures, parameters and refinement details are discussed in more detail in the $\mathrm{SI}$ (Table S1).

It should be noted that $\mathrm{C}$, with two dP ligands attached to either side of the POM core (R-POM-R), represents a new member of a family of related compounds based on the Anderson-Evans structure functionalised with $\mathrm{dP}$ that were recently reported by Wei et al and, therefore, it further demonstrates the versatility of this POM scaffold. ${ }^{34}$ The formation of a dumbbell-like structure (POM-R-POM) was reported to be obtained when the ratio of $\mathrm{CrMo}_{6}$ and $\mathrm{dP}$ was set to 2:1 while changing the ratio to $1: 1.4$ gave rise to the mono-functionalised $\mathrm{CrMo}_{6}$ (POM-R). However, isolation of the symmetrical bis-functionalised $\mathrm{CrMo}_{6} \mathrm{HPOM}$ was not reported by Wei et al. Nevertheless, through the procedure reported herein, using a higher temperature and a 1:4 ratio of $\mathrm{CrMo}_{6}$ to $\mathrm{dP}$, it was possible to synthesize $\mathbf{C}$ without any side products,

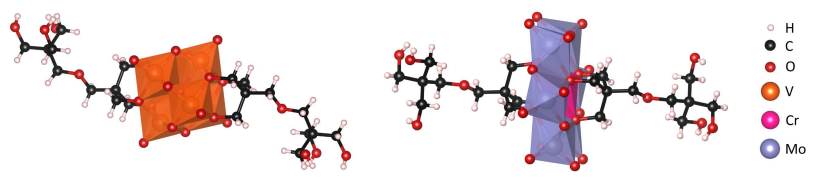

Figure 3 Mixed ball-stick and polyhedral representation of the structures of $\mathbf{L}$ (left) and $\mathbf{C}$ (right) as determined by single crystal $\mathrm{X}$-ray diffraction. TBA counterions and the positional disorder were omitted for clarity. 
showing that controlling the ratio of starting materials and the temperature allows for the formation of different functionalised structures.

\section{Synthesis \& characterisation of D-terminal POM-POM hybrids}

The POM-POM hybrids formed via post-functionalisation of $\mathbf{L}$ or C with $\mathbf{D}$ were obtained by refluxing the POM linker with $\mathrm{TBA}_{5} \mathrm{H}_{4}\left[\mathrm{P}_{2} \mathrm{~V}_{3} \mathrm{~W}_{15} \mathrm{O}_{62}\right]$ for one week in dry acetonitrile under an inert argon atmosphere while the reaction mixture was kept in the dark to prevent photo-induced side reactions. In this way, $\mathrm{TBA}_{12} \mathrm{H}_{2}\left[\mathrm{~V}_{6} \mathrm{O}_{13}\left\{\left(\mathrm{OCH}_{2}\right)_{3} \mathrm{CCH}_{2} \mathrm{OCH}_{2} \mathrm{C}\left(\mathrm{CH}_{2} \mathrm{O}\right)_{3}\left(\mathrm{P}_{2} \mathrm{~V}_{3} \mathrm{~W}_{15} \mathrm{O}_{59}\right)\right\}_{2}\right]$ (DLD) and $\mathrm{TBA}_{12} \mathrm{H}_{3}\left[\mathrm{CrMo}_{6} \mathrm{O}_{18}\left\{\left(\mathrm{OCH}_{2}\right)_{3} \mathrm{CCH}_{2} \mathrm{OCH}_{2} \mathrm{C}\left(\mathrm{CH}_{2} \mathrm{O}\right)_{3}\left(\mathrm{P}_{2} \mathrm{~V}_{3} \mathrm{~W}_{15} \mathrm{O}_{59}\right)\right\}_{2}\right]$ (DCD) were obtained in high yields from $L$ and $C$ respectively. The reactions were left running for a week to ensure the POM linker fully reacted, but evidence of the formed POM-POM hybrid with only trace amounts of the starting materials was observed by multinuclear NMR after refluxing for just over an hour, which suggests that a shorter reaction time is possible.

As shown in Figure 4, evidence for the attachment of the free triol group of $\mathbf{L}$ to $\mathbf{D}$ could be clearly seen from changes in the chemical shift of the peaks in the ${ }^{1} \mathrm{H},{ }^{13} \mathrm{C},{ }^{51} \mathrm{~V}$ and ${ }^{31} \mathrm{P}$ NMR spectra of DLD (Figure S16-18) with respect to the starting materials. In ${ }^{1} \mathrm{H} N M R$, a significant downfield shift from 3.46 ppm to $5.45 \mathrm{ppm}$ was observed for the $-\mathrm{CH}_{2}$-O- protons of the triol group, corresponding to binding of the tripodal anchor to the $V_{3}$ cap of $\mathbf{D}$. To a lesser extent, a shift was also observed for the peaks of the adjoining ethyl protons in the bridging $-\mathrm{CH}_{2}-\mathrm{O}$ $\mathrm{CH}_{2}$ - ether group. Similar changes were also observed in the ${ }^{13} \mathrm{C}$ NMR spectrum of DLD with respect to $L$. In addition, ${ }^{51} \mathrm{~V}$ NMR showed a major downfield shift from $-585 \mathrm{ppm}$ to $-538 \mathrm{ppm}$ for the peak belonging to the $V_{3}$ cap of $D$, as a result of functionalisation, while the peak of the $V_{6}$ core remained relatively unchanged at $-497 \mathrm{ppm}$. The integration of both peaks in the ${ }^{51} \mathrm{~V}$ NMR spectrum was approximately the same, which is indicative of the formation of a symmetrical POM-POM hybrid with two $V_{3}$ caps attached to either side of the $V_{6}$ core.
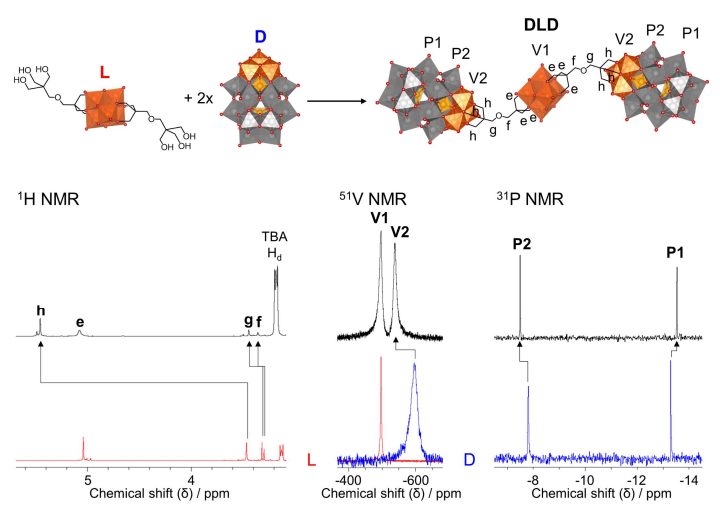

Figure $\mathbf{5}$ Synthesis of DLD from $\mathbf{L}$ and $\mathbf{D}$ (top) and the corresponding ${ }^{1} \mathrm{H},{ }^{51} \mathrm{~V}$ and ${ }^{31} \mathrm{P}$ NMR spectra (bottom; ordered from left to right) of the POM-POM hybrid (black) and the starting materials (red for $\mathbf{L}$ and blue for $\mathbf{D}$ ) illustrating the changes in the chemical shifts due to POM post-functionalisation of $L$.
Moreover, ${ }^{31} \mathrm{P}$ NMR showed only two peaks at $-7.51 \mathrm{ppm}$ and $13.55 \mathrm{ppm}$, which were observed to shift slightly from the typical chemical shifts of $\mathbf{D}$, further confirming functionalisation and the structural integrity of the Wells-Dawson POM structure. The integrity of the POM cores was also confirmed by IR spectroscopy (Figure S15) from the peak at $1084 \mathrm{~cm}^{-1}$ due to the $\left\{\mathrm{PO}_{4}\right\}$ template of the Wells-Dawson structure and the peaks in the range $400-1000 \mathrm{~cm}^{-1}$ due to $v \mathrm{M}=\mathrm{O}$ and $\vee \mathrm{M}-\mathrm{O}-\mathrm{M}$ vibrations ( $\mathrm{M}=\mathrm{V}$ or $\mathrm{W}) .{ }^{47,53,54}$ In addition, the UV-Vis absorbance spectrum of DLD (Figure S19) showed a significantly higher absorbance compared to the 1:2 mixture of $\mathbf{L}$ and $\mathbf{D}$ with the same total concentration. However, after normalisation with respect to the maximum absorbance, the spectra matched very well, further confirming that DLD is indeed a 1:2 combination of $L$ and D. Hence, distinct spectroscopic changes evidence the formation of a novel POM-POM hybrid via the covalent attachment of the Lindqvist and Wells-Dawson POM structures, thereby combining their characteristic properties in a single discrete hybrid structure. ${ }^{16,30,36,55}$

The formation of DCD was also observed by multinuclear NMR and the integrity of the POM cores was confirmed by IR spectroscopy. IR showed peaks in the range $400-1000 \mathrm{~cm}^{-1}$ due to $v \mathrm{M}=\mathrm{O}$ and $v \mathrm{M}-\mathrm{O}-\mathrm{M}$ vibrations $(\mathrm{M}=\mathrm{Mo}, \mathrm{V}$ or $\mathrm{W}$ ) which are clearly due to both the Anderson-Evans and Wells-Dawson POM cores (Figure S21). Furthermore, as observed with DLD, the UVVis absorbance spectrum of DCD (Figure S24) was dominated by the $\mathrm{O} \rightarrow \mathrm{W}^{6+}$ and $\mathrm{O} \rightarrow \mathrm{V}^{5+} \mathrm{LMCT}$ bands of $\mathbf{D} .^{32}$ Similarly, DCD also displayed a higher absorbance than a 1:2 mixture of $\mathbf{C}$ and $\mathbf{D}$ with the same total concentration, but the normalised spectra gave an excellent match, indicating that DCD is indeed a result of a 1:2 combination of $\mathbf{C}$ and $\mathbf{D}$. Additionally, a major shift in the peak corresponding to the $V_{3}$ cap from $-585 \mathrm{ppm}$ to -539 ppm was also observed by ${ }^{51} \mathrm{~V}$ NMR as a result of functionalisation (Figure 5; Figure S23). Likewise, ${ }^{31} \mathrm{P}$ NMR gave only two peaks at $-7.58 \mathrm{ppm}$ and $-13.51 \mathrm{ppm}$ corresponding to the functionalised Wells-Dawson structure (Figure 5; Figure S22). Moreover, the peak at $-7.58 \mathrm{ppm}$, which is due to the ${ }^{31} \mathrm{P}$

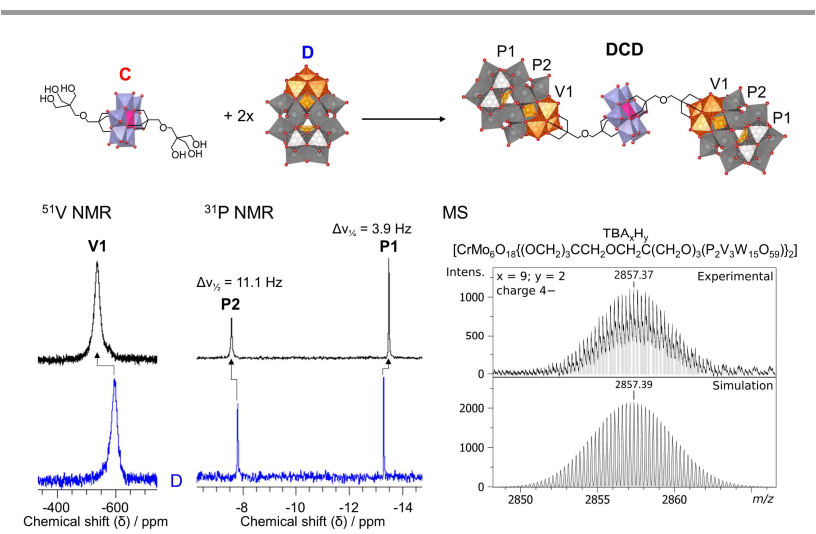

Figure 4 Synthesis of $\mathbf{D C D}$ from $\mathbf{C}$ and $\mathbf{D}$ (top) together with the corresponding ${ }^{51} \mathrm{~V}$ and ${ }^{31}$ P NMR spectra (bottom left) of the POM-POM hybrid (black) and of D (blue) as well as the experimental and simulated cryo-MS spectra for DCD (bottom right). 
environment closest to the $V_{3}$ cap, had a half-width $\left(\Delta v_{1 / 2}\right)$ of 11.1 $\mathrm{Hz}$, which was significantly broader than the second ${ }^{31} \mathrm{P}$ peak at $-13.51 \mathrm{ppm}$, and was also much broader than the peaks in the ${ }^{31} \mathrm{P}$ NMR spectra of DLD and $\mathrm{D}$, which had a $\Delta \mathrm{v}_{1 / 2}$ of around 4-7 $\mathrm{Hz}$. This broadening of the most deshielded peak is caused by the paramagnetic $\mathrm{Cr}^{3+}$ centre of the Anderson-Evans structure and clearly indicates the proximity of the POMs through their covalent attachment. Moreover, this suggests that the combination of $\mathbf{C}$ and $\mathbf{D}$ could potentially be exploited to probe biomolecules, such as proteins, due to ${ }^{1} \mathrm{H}$ paramagnetic relaxation enhancement resulting from $\mathbf{C}$ and the favourable interactions which can take place between proteins and the Wells-Dawson structure. ${ }^{56,57}$

The successful formation of both DLD and DCD was also confirmed by Ultra High Resolution cryo-mass spectrometry (UHR cryo-MS), which gave several peaks corresponding to the POM-POM hybrid structures with different numbers of protons and TBA as counter-cations (Figure 5; Table S2-S3; Figure S14 \& S20). Their composition was also further confirmed by elemental analysis. To the extent of our knowledge, these novel heterometallic POM-POM hybrids represent the first examples of the covalent attachment of other POM structures onto a Wells-Dawson type POM, and DCD in particular demonstrates the high number of different metal centres that can be combined in this way.

\section{Synthesis \& characterisation of A-terminal POM-POM hybrids}

Similar to the formation of DLD and DCD, the synthesis of POMPOM hybrids with Anderson-Evans terminal groups was performed by refluxing the $\mathrm{dP}$-functionalised POM linker and $\mathbf{A}$. In this way, an additional two new POM-POM hybrids were obtained:

\section{$\mathrm{TBA}_{8}\left[\mathrm{~V}_{6} \mathrm{O}_{13}\left\{\left(\mathrm{OCH}_{2}\right)_{3} \mathrm{CCH}_{2} \mathrm{OCH} \mathrm{C}_{2} \mathrm{C}\left(\mathrm{CH}_{2} \mathrm{O}\right)_{3}\left(\mathrm{Al}(\mathrm{OH})_{3} \mathrm{Mo}_{6} \mathrm{O}_{18}\right)\right\}_{2}\right]$}

\section{(ALA)}

$\mathrm{TBA}_{9}\left[\mathrm{CrMo}_{6} \mathrm{O}_{18}\left\{\left(\mathrm{OCH}_{2}\right)_{3} \mathrm{CCH}_{2} \mathrm{OCH}_{2} \mathrm{C}\left(\mathrm{CH}_{2} \mathrm{O}\right)_{3}\left(\mathrm{Al}(\mathrm{OH})_{3} \mathrm{Mo}_{6} \mathrm{O}_{18}\right)\right\}_{2}\right]$

(ACA). However, the syntheses were performed in water due to the higher reported reactivity of the labile $\mathrm{OH}$ groups of $\mathbf{A}$ towards substitution in aqueous media with respect to that in organic solvents. ${ }^{35}$ Hence, taking into account the insolubility of the TBA salts of $\mathbf{C}$ and $\mathbf{L}$ in water, an ion metathesis procedure involving precipitation of the $\mathrm{Na}$-salt by addition of $\mathrm{NaClO}_{4}$ to the TBA-salts in acetonitrile - was employed to obtain the water-soluble sodium salts of these compounds, which were characterised by multinuclear NMR, UV-Vis and/or IR spectroscopy (Figures S10-S13). ${ }^{58}$

The synthesis of ALA was confirmed by multinuclear NMR, MS, UV-Vis, IR, and elemental analysis. Functionalisation of $\mathbf{L}$ was observed by ${ }^{1} \mathrm{H} N M R$, which showed a downfield shift of the $-\mathrm{OCH}_{2}$ - protons from around $3.46 \mathrm{ppm}$ for $\mathbf{L}$ to $4.50 \mathrm{ppm}$ for ALA (Figure 6; Figure S28). Similar changes were also observed from the ${ }^{13} \mathrm{C}$ NMR spectra, which showed a downfield shift in the corresponding carbon environment from $63.70 \mathrm{ppm}$ for $\mathbf{L}$ to $76.89 \mathrm{ppm}$ for ALA (Figure S29). In addition, the peaks in negative mode ESI-MS of ALA in acetonitrile could be assigned to ALA with different numbers of protons and TBA as countercations giving rise to species with charges of 2- or 3- (Figure S25; Table S4). However, the spectra obtained by cryo-MS suggest that ALA does not ionise well or is not particularly stable under the measurement conditions used since only one profile centred at $\mathrm{m} / \mathrm{z} 3383.87$ (Figure S26) could be tentatively assigned to the mono-anionic species with 2 TBA and 5 protons as counter ions ([TBA $\left.{ }_{2} \mathrm{H}_{5} \mathrm{ALA}\right]$; ; calcd. $\left.\mathrm{m} / \mathrm{z}=3384.05\right)$. The difference between the calculated and observed $m / z$ is also significantly larger than expected for ultra-high resolution measurements preventing a confident assignment of the cryoMS spectra. Nevertheless, similar to DLD and DCD, the UV-Vis absorbance spectrum of ALA (Figure S32) displayed a higher absorbance than a $1: 2$ mixture of $\mathbf{L}$ and $\mathbf{A}$ with the same total concentration while the normalised spectra matched fairly well, with the exception of an additional peak at $218 \mathrm{~nm}$. This extra peak at $218 \mathrm{~nm}$ is due to the functionalisation of $\mathbf{A}$, which causes a hypochromic shift in the absorbance peak originating from the $\mathrm{O} \rightarrow \mathrm{Mo}^{6+}$ LMCT that was also observed for the functionalisation of $\mathrm{CrMo}_{6}$ to form $\mathrm{C}$. This further confirms that ALA is composed of a 1:2 combination of $\mathbf{L}$ and $\mathbf{A}$ via covalent attachment. The peaks at 1132 and $1035 \mathrm{~cm}^{-1}$ in the IR spectrum (Figure S27) due to $\mathrm{C}-\mathrm{O}$ stretching vibrations are also indicative of functionalisation, and the peaks in the region $400-1000 \mathrm{~cm}^{-1}$ originating from $\vee \mathrm{M}=\mathrm{O}$ and $\vee \mathrm{M}-\mathrm{O}-\mathrm{M}$ vibrations $(\mathrm{M}=\mathrm{V}$ or $\mathrm{Mo}$ ) confirm the presence of both POM cores. The integrity of the $V_{6}$ and $\mathrm{AlMo}_{6} \mathrm{POM}$ cores after post-functionalisation were also evidenced from single sharp peaks at $-495 \mathrm{ppm}$ and $15.69 \mathrm{ppm}$ in the ${ }^{51} \mathrm{~V} N M R$ and ${ }^{27} \mathrm{Al}$ NMR spectra, respectively (Figure S30S31). Moreover, the attachment of $A$ to $L$ resulted in a decrease in the translational diffusion coefficient $\left(D_{\text {diff }}\right)$ from $921 \mu \mathrm{m}^{2} / \mathrm{s}$ (L) to $472 \mu \mathrm{m}^{2} / \mathrm{s}$ (ALA) as determined from all peaks corresponding to the POM-POM hybrid by ${ }^{1} \mathrm{H}$ 2D Diffusion Ordered NMR spectroscopy (DOSY), which shows that all peaks correspond to the same species and that ALA is significantly larger than L (Figure 6). It is worth noting that a similar decrease in $D_{\text {diff }}$ compared to $L$ was also observed for DLD, but DLD gave an even lower $D_{\text {diff }}$ due to the larger size of $\mathbf{D}$ with respect to $\mathbf{A}$. In fact, the hydrodynamic radius $(r)$ determined from the

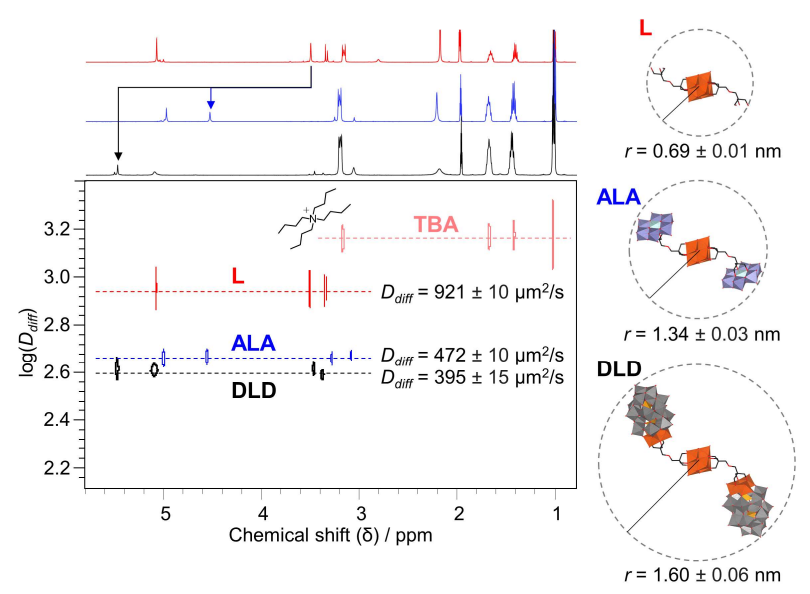

Figure 6 Overlayed ${ }^{1} \mathrm{H}$ 2D DOSY NMR spectra of L, ALA and DLD labelled with the translational diffusion coefficient $\left(D_{\text {diff }}\right)$ used to determine the hydrodynamic radius $(r)$ for each structure, as shown on the right, and the corresponding ${ }^{1} \mathrm{H} 1 \mathrm{D}$ NMR spectra shown at the top. 
observed $D_{\text {diff }}$ using the Stokes-Einstein equation showed the expected increase in size from $0.69 \pm 0.01 \mathrm{~nm}$ for $L$ to $1.34 \pm$ $0.03 \mathrm{~nm}$ for ALA and $1.60 \pm 0.06 \mathrm{~nm}$ for DLD. These values also match fairly well with the crystal structure of $\mathbf{L}$ and the simulated structures of ALA and DLD, which were based on a combination of the structure of $\mathbf{L}$ with the crystal structures of A (ICSD 415139) or D (CCDC 675452), from which $r$ was estimated to be $0.96,1.19$, and $1.99 \mathrm{~nm}$ respectively. ${ }^{55,59}$

Based on the successful isolation of DCD and following a similar procedure used for the synthesis of ALA, the synthesis of a triple Anderson-Evans POM-POM hybrid structure based on C with terminal A was also attempted. Negative mode ESI-MS (Figure S33) of the isolated product gave a peak centred around $\mathrm{m} / \mathrm{z} 1931.61$ which can be attributed to the di-anionic POM with 2 TBA and 5 protons as counter ions $\left(\left[\mathrm{TBA}_{2} \mathrm{H}_{5} \mathrm{ACA}+(\mathrm{ACN})+2\left(\mathrm{H}_{2} \mathrm{O}\right)\right]^{2-;}\right.$ calcd. $\left.\mathrm{m} / \mathrm{z}=1931.40\right)$ confirming the successful synthesis of ACA. However, ACA exhibited a similar behaviour to that observed for ALA under the cryo-MS measurement conditions since only one profile centred at $\mathrm{m} / \mathrm{z} 4027.85$ (Figure S34) could correspond to the mono-anionic species with 3 TBA and 5 protons as counter ions ([TBA $\left.\mathrm{H}_{5} \mathrm{ACA}\right]$; calcd. $\mathrm{m} / \mathrm{z}=4028.03$ ) but, like with ALA, the difference between the calculated and observed $\mathrm{m} / \mathrm{z}$ is significantly larger than expected for ultra-high resolution measurements and, therefore, this profile could not be unambiguously assigned. Furthermore, due to the paramagnetic nature of the $\mathrm{Cr}^{3+}$ centre, NMR analysis was limited to ${ }^{13} \mathrm{C}$ and ${ }^{27} \mathrm{Al}$ NMR (Figure S36-37). ${ }^{13} \mathrm{C}$ NMR of ACA showed that grafting of the free triol group of $\mathbf{C}$ onto $\mathbf{A}$ resulted in the disappearance of the peak at $64.21 \mathrm{ppm}$, which is due to the $-\mathrm{CH}_{2} \mathrm{OH}$ groups of $\mathrm{C}$, and the appearance of a peak at 77.31 ppm corresponding to the formation of $-\mathrm{CH}_{2} \mathrm{O}-\mathrm{Al}$, as seen for ALA. However, only one additional peak due to ACA at 42.06 $\mathrm{ppm}$, corresponding to the quaternary carbon furthest from the $\mathrm{CrMo}_{6}$ core, could be observed since the other carbon environments are too close to the $\mathrm{Cr}^{3+}$ centre and, therefore, did not give rise to noticeable peaks. Nevertheless, ${ }^{27} \mathrm{Al} N M R$ gave a single peak at $15.64 \mathrm{ppm}$ due to the functionalised $\mathrm{AlMo}_{6}$ POM core, which also closely matches with the ${ }^{27} \mathrm{Al} N M R$ spectrum of ALA. Additionally, the characteristic peaks of the Anderson-Evans structure in the IR spectrum at 937 ( $v \mathrm{Mo}=\mathrm{O}$, s), $916(v \mathrm{Mo}=\mathrm{O}, \mathrm{s}), 899$ ( $v \mathrm{Mo}=\mathrm{O}, \mathrm{s})$ and 650 ( $v$ Mo-O-Mo, vs) $\mathrm{cm}^{-1}$ confirm the integrity of the POM structures (Figure S35). Moreover, the UV-Vis absorbance spectrum (Figure S38) shows that ACA consists of a 1:2 combination of $\mathbf{C}$ and $\mathbf{A}$ via covalent attachment since it displayed a higher absorbance than a 1:2 mixture of $\mathbf{C}$ and $\mathbf{A}$ with the same total concentration while the normalised spectra matched fairly well, with only slight differences due to the functionalisation of $\mathbf{A}$. The elemental composition of the isolated compound also displays the expected stoichiometry for $\mathrm{C}, \mathrm{H}, \mathrm{N}, \mathrm{Al}, \mathrm{Mo}$ and $\mathrm{Cr}$ as shown in the SI.

\section{Thermal stability}

The thermal stability of all new HPOMs reported in this work was evaluated by Thermogravimetric Analysis (TGA) under an $\mathrm{N}_{2}$ atmosphere between $30{ }^{\circ} \mathrm{C}$ and $630{ }^{\circ} \mathrm{C}$. All HPOMs were

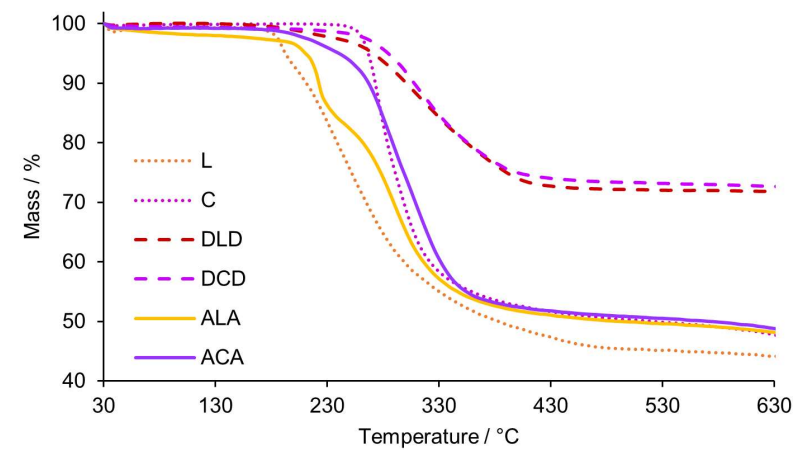

Figure 7 TGA profiles (top) showing the weight loss with increasing temperature for the building blocks, L and C, and their corresponding POM-POM hybrids: DLD, DCD, ALA, and ACA.

Table 1 Residual mass of the POM-POM hybrids at around $630^{\circ} \mathrm{C}$.

\begin{tabular}{ccc} 
HPOM & Calcd. res. mass / \% & Observed res. mass / \% \\
\hline DLD & 71.82 & 71.85 \\
DCD & 72.75 & 72.63 \\
ALA & 49.59 & 48.01 \\
ACA & 51.1 & 48.63 \\
\hline
\end{tabular}

observed to remain stable below $180^{\circ} \mathrm{C}$, which is comparable to the previously reported stability of similar structures. ${ }^{34,35,60}$ Between 180 and $500^{\circ} \mathrm{C}$ a weight loss was observed in the TGA profiles of the HPOMs, indicating their decomposition due to loss of the organic components (Figure 7). L was the least stable as it began to significantly decompose just above $180^{\circ} \mathrm{C}$ while, in contrast, $\mathbf{C}$ was much more stable and only started decomposing above $250{ }^{\circ} \mathrm{C}$. Furthermore, bis-functionalisation to form $\mathbf{C}$ results in a higher thermal stability compared to the corresponding mono-functionalised form and having $\mathrm{Cr}^{3+}$ as the heteroatom improves the stability with respect to the equivalent bis-functionalised structure with $\mathrm{Mn}^{3+} .34$ The higher thermal stability of the Anderson-Evans building block was also reflected in the higher stability of ACA compared to ALA, each of which had similar stabilities compared to their respective building-blocks. However, the highest stability was observed for the DLD and DCD, which only decomposed above $250{ }^{\circ} \mathrm{C}$. As previously observed for the other HPOMs based on $\mathrm{CrMo}_{6}, \mathrm{DCD}$ was also slightly more stable than DLD with no major decomposition until $265^{\circ} \mathrm{C}$. In addition, DCD demonstrated a higher thermal stability than the homogenous "dumbbell" and "triangular" POM-POM hybrids based on $\mathrm{P}_{2} \mathrm{~V}_{3} \mathrm{~W}_{15}$ POMs covalently linked with purely organic linkers, which showed significant decomposition just above $200{ }^{\circ} \mathrm{C} .{ }^{30,33}$ Moreover, for all POM-POM hybrids the residual weight at $630{ }^{\circ} \mathrm{C}$ after complete loss of the organic part was in good agreement with the calculated values for the loss of all TBA counter ions and the $\mathrm{dP}$ linker as shown in Table 1, further confirming their structures. 


\section{Conclusions}

In summary, a set of novel metal-oxo cluster building-blocks were synthesised for the formation of a wide variety of hybrid structures combining different inorganic cluster types. The first examples of POM-POM hybrid structures combining the WellsDawson POM structure with Lindqvist and Anderson-Evans POMs were successfully obtained as confirmed by multinuclear NMR, IR, UV-Vis, MS and elemental analysis. Furthermore, it was also shown that this method can be used to link together Anderson-Evans and Lindqvist POMs, as well as Anderson-Evans structures with different heteroatoms. All POM triads were thermally stable until $180{ }^{\circ} \mathrm{C}$, and showed in general higher thermal stability compared to the HPOM structures linked by only organic ligands. Moreover, the proposed postfunctionalisation strategy for the formation of these heterometallic hybrid structures composed of multiple inorganic components is relatively simple and results in high yields without the need of additional reagents. Additionally, the same strategy could be applied to an even wider range of metal oxo-clusters and, in principle, it could also be employed to produce more complex structures such as polymers containing different POMs linked together, as well as asymmetric POMPOM hybrids containing two or more different types of POM structures $\left(\mathrm{POM}_{1}-\mathrm{POM}_{2}-\mathrm{POM}_{3}--\mathrm{POM}_{n}\right)$ allowing for the controlled design of compounds with the desired composition. For example, the Anderson-Evans structure can accommodate a large variety of different central heteroatoms, including most first-row transition metals and even some p-block elements (e.g., $\mathrm{X}=\mathrm{Mn}, \mathrm{Fe}, \mathrm{Co}, \mathrm{Ni}, \mathrm{Cu}, \mathrm{Zn}, \mathrm{Ga}, \mathrm{Al}, \mathrm{Te}$, etc.), resulting in the formation of either bis- or mono-functionalised structures that can be combined to tune the properties of the material based on the choice of the metal centre. ${ }^{15}$ The Lindqvist structure also offers additional structural variability since it can be mono-, bis, tri- or tetra- functionalised, depending on the oxidation state and composition of the metal centres $\left(\left[\mathrm{V}_{3} \mathrm{Mo}_{3} \mathrm{O}_{16}\left\{\left(\mathrm{OCH}_{2}\right)_{3} \mathrm{C}-\mathrm{R}\right\}\right]\right.$; $\left[\mathrm{V}_{6} \mathrm{O}_{19-3 x-y}(\mathrm{OH})_{y}\left\{\left(\mathrm{OCH}_{2}\right)_{3} \mathrm{C}-\mathrm{R}\right\}_{x}\right]$ where $x=2,3$, and 4). ${ }^{14,17,61}$ Furthermore, the vanadium and nickel substituted Keggin structures $\left(\left[\mathrm{XM}_{12} \mathrm{O}_{40}\right]^{\mathrm{n}-}\right)$ can also be functionalised with polyols in the same way as for the Wells-Dawson structure. ${ }^{62,63}$ In addition, tailoring of the structures formed via this strategy is not limited to the inorganic components, since employing different polyols with other functional groups as organic linkers could also be used for added functionality. Therefore, the novel strategy proposed here based on metal-oxo clusters functionalised with polyols allows them to be used as platforms for the combination of a wide variety of other metal-oxo structures via covalent attachment. Moreover, this strategy could ideally also be extended to functional surfaces or nanoparticles and even to the non-covalent self-assembly of species via the free triol groups. ${ }^{21-26,64,65}$

\section{Author Contributions}

D.E.S.M., M.A.M., A.V.A., and S.L. performed the synthesis and characterisation of the novel compounds. The cryo-MS measurements were performed and interpreted with the assistance of I.I.B. The crystal structures were solved by L.V.M. T.N.P.V. helped with the design and interpretation of the experiments. The manuscript was written through contributions of D.E.S.M., M.A.M., A.V.A., S.L. and T.N.P.V. All authors have given approval to the final version of the manuscript.

\section{Conflicts of interest}

There are no conflicts to declare.

\section{Acknowledgements}

We thank KU Leuven and the Research Foundation Flanders (FWO) for funding. D.E.S.M. (83523/1183021N) and M.A.M. $(203282 / 1279721 N)$ thank the FWO for fellowships. L.V.M. thanks the Hercules Foundation for supporting the purchase of the diffractometer through project AKUL/09/ 0035.

\section{Notes and references}

1 L. Rozes and C. Sanchez, Chem. Soc. Rev., 2011, 40, 10061030.

2 C. Sanchez, P. Belleville, M. Popall and L. Nicole, Chem. Soc. Rev., 2011, 40, 696.

3 M. Hutin, M. H. Rosnes, D.-L. Long and L. Cronin, in Comprehensive Inorganic Chemistry II, Elsevier, 2013, vol. 2, pp. 241-269.

4 S.-S. Wang and G.-Y. Yang, Chem. Rev., 2015, 115, 48934962.

5 Y.-F. Song, Polyoxometalate-Based Assemblies and Functional Materials, Springer International Publishing, Cham, 2018, vol. 176.

6 J. T. Rhule, C. L. Hill, D. A. Judd and R. F. Schinazi, Chem. Rev., 1998, 98, 327-358.

7 D.-L. Long, E. Burkholder and L. Cronin, Chem. Soc. Rev., 2007, 36, 105-121.

8 M. Stuckart and K. Y. Monakhov, Chem. Sci., 2019, 10, 4364-4376.

9 Y. Ji, L. Huang, J. Hu, C. Streb and Y.-F. Song, Energy Environ. Sci., 2015, 8, 776-789.

10 A. Proust, B. Matt, R. Villanneau, G. Guillemot, P. Gouzerh and G. Izzet, Chem. Soc. Rev., 2012, 41, 7605.

11 A. Proust, R. Thouvenot and P. Gouzerh, Chem. Commun., 2008, 1837.

12 J. Zhang, Y. Huang, G. Li and Y. Wei, Coord. Chem. Rev., 2019, 378, 395-414.

13 A. Dolbecq, E. Dumas, C. R. Mayer and P. Mialane, Chem. Rev., 2010, 110, 6009-6048.

O. Linnenberg, A. Kondinski and K. Y. Monakhov, in Supramolecular Systems: Chemistry, Types and Applications, 2017, pp. 39-66.

15 A. Blazevic and A. Rompel, Coord. Chem. Rev., 2016, 307, 42-64.

16 Y. Hou and C. L. Hill, J. Am. Chem. Soc., 1993, 115, 1182311830.

17 A. V Anyushin, A. Kondinski and T. N. Parac-Vogt, Chem. 
Soc. Rev., 2020, 27-29.

S. Vanhaecht, T. Quanten and T. N. Parac-Vogt, Inorg. Chem., 2017, 56, 3095-3101.

S. Vanhaecht, T. Quanten and T. N. Parac-Vogt, Dalt. Trans., 2017, 46, 10215-10219. S. Vanhaecht, J. Jacobs, L. Van Meervelt and T. N. ParacVogt, Dalt. Trans., 2015, 44, 19059-19062.

R. J. Errington, S. S. Petkar, B. R. Horrocks, A. Houlton, L. H. Lie and S. N. Patole, Angew. Chemie Int. Ed., 2005, 44, 1254-1257.

B. J. S. Johnson and A. Stein, Inorg. Chem., 2001, 40, 801808.

A. W. H. Lee and B. D. Gates, Langmuir, 2016, 32, 72847293.

A. W. H. Lee and B. D. Gates, Langmuir, 2017, 33, 8707-

8715.

Y. Wang and I. A. Weinstock, Chem. Soc. Rev., 2012, 41, 7479.

H. J. H. Kang, R. F. Ali, M. T. Y. Paul, M. J. Radford, I. Andreu, A. W. H. Lee and B. D. Gates, Chem. Commun., 2019, 55, 10452-10455.

M.-P. Santoni, A. K. Pal, G. S. Hanan, M.-C. Tang, K. Venne, A. Furtos, P. Ménard-Tremblay, C. Malveau and B. Hasenknopf, Chem. Commun., 2012, 48, 200-202. M. S. Centellas, M. Piot, R. Salles, A. Proust, L. Tortech, D. Brouri, S. Hupin, B. Abécassis, D. Landy, C. Bo and G. Izzet, Chem. Sci., 2020, 11, 11072-11080.

H. Zeng, G. R. Newkome and C. L. Hill, Angew. Chemie, 2000, 112, 1841-1844.

C. P. Pradeep, M. F. Misdrahi, F.-Y. Li, J. Zhang, L. Xu, D.-L. Long, T. Liu and L. Cronin, Angew. Chemie, 2009, 121, 8459-8463.

P. Yin, T. Li, R. S. Forgan, C. Lydon, X. Zuo, Z. N. Zheng, B. Lee, D. Long, L. Cronin and T. Liu, J. Am. Chem. Soc., 2013, 135, 13425-13432.

T. Auvray, M.-P. Santoni, B. Hasenknopf and G. S. Hanan, Dalt. Trans., 2017, 46, 10029-10036.

C. P. Pradeep, F.-Y. Li, C. Lydon, H. N. Miras, D.-L. Long, L. Xu and L. Cronin, Chem. - A Eur. J., 2011, 17, 7472-7479.

Q. Xu, S. Yuan, L. Zhu, J. Hao and Y. Wei, Chem. Commun., 2017, 53, 5283-5286.

H. Ai, Y. Wang, B. Li and L. Wu, Eur. J. Inorg. Chem., 2014, 2014, 2766-2772.

K. P. Sullivan, W. A. Neiwert, H. Zeng, A. K. Mehta, Q. Yin, D. A. Hillesheim, S. Vivek, P. Yin, D. L. Collins-Wildman, E. R. Weeks, T. Liu and C. L. Hill, Chem. Commun., 2017, 53, 11480-11483.

M. Lu, Y. Wei, B. Xu, C. F.-C. Cheung, Z. Peng and D. R. Powell, Angew. Chemie Int. Ed., 2002, 41, 1566-1568. J. L. Stark, A. L. Rheingold and E. A. Maatta, J. Chem. Soc. Chem. Commun., 1995, 1165.

J. Zhang, J. Hao, Y. Wei, F. Xiao, P. Yin and L. Wang, J. Am. Chem. Soc., 2010, 132, 14-15.

J. Zhang, P. Yin, J. Hao, F. Xiao, L. Chen and Y. Wei, Chem. A Eur. J., 2012, 18, 13596-13599.

A. Bayaguud, J. Zhang, R. N. N. Khan, J. Hao and Y. Wei, Chem. Commun., 2014, 50, 13150-13152.
J. Zhang, F. Xiao, J. Hao and Y. Wei, Dalt. Trans., 2012, 41, 3599.

H. An, J. Zhang, S. Chang, Y. Hou and Q. Zhu, Inorg. Chem., 2020, 59, 10578-10590. 4042-4045.

45 I. Fa Bamba, C. Falaise, G. K. Gbassi, P. Atheba, M. Haouas and E. Cadot, J. Coord. Chem., 2020, 73, 2567-2578. C. Qin and J. Zubieta, Inorganica Chim. Acta, 1992, 198200, 95-110.

P. Wu, J. Chen, P. Yin, Z. Xiao, J. Zhang, A. Bayaguud and Y. Wei, Polyhedron, 2013, 52, 1344-1348.

P. R. Marcoux, B. Hasenknopf, J. Vaissermann and P. Gouzerh, Eur. J. Inorg. Chem., 2003, 2003, 2406-2412.

B. Hasenknopf, R. Delmont, P. Herson and P. Gouzerh, Eur. J. Inorg. Chem., 2002, 2002, 1081-1087.

C. G. Lin, W. Chen, D. L. Long, L. Cronin and Y. F. Song, Dalt. Trans., 2014, 43, 8587-8590.

51 J. Zhang, Y. Huang, J. Zhang, S. She, J. Hao and Y. Wei, Dalt. Trans., 2014, 43, 2722-2725.

52 J. Zhang, Z. Zhao, J. Zhang, S. She, Y. Huang and Y. Wei, Dalt. Trans., 2014, 43, 17296-17302.

53 Q. Chen, D. P. Goshorn, C. P. Scholes, X. L. Tan and J. Zubieta, J. Am. Chem. Soc., 1992, 114, 4667-4681.

L. E. Briand, H. J. Thomas and G. T. Baronetti, Appl. Catal. A Gen., 2000, 201, 191-202.

C. P. Pradeep, D.-L. Long, G. N. Newton, Y.-F. Song and L. Cronin, Angew. Chemie Int. Ed., 2008, 47, 4388-4391. J. Iwahara, C. D. Schwieters and G. M. Clore, J. Am. Chem. Soc., 2004, 126, 12800-12808. L. Vandebroek, Y. Mampaey, S. Antonyuk, L. Van Meervelt and T. N. Parac-Vogt, Eur. J. Inorg. Chem., 2019, 2019, 506511.

D. E. Salazar Marcano, S. Lentink, M. A. Moussawi and T. N. Parac-Vogt, Inorg. Chem., 2021, 60, 10215-10226. V. Shivaiah and S. K. Das, J. Chem. Sci., 2005, 117, 227-233. H. Jia, Q. Li, A. Bayaguud, S. She, Y. Huang, K. Chen and Y. Wei, Sci. Rep., 2017, 7, 2-10.

61 S. Spillane, R. Sharma, A. Zavras, R. Mulder, C. A. Ohlin, L. Goerigk, R. A. J. O'Hair and C. Ritchie, Angew. Chemie Int. Ed., 2017, 56, 8568-8572.

D. Karimian, B. Yadollahi and V. Mirkhani, Microporous Mesoporous Mater., 2017, 247, 23-30. X.-X. Li, S.-T. Zheng, W.-H. Fang and G.-Y. Yang, Inorg. Chem. Commun., 2011, 14, 1541-1545.

64 C. Sperandio, J. Rodriguez and A. Quintard, Chem. Sci., 2020, 11, 1629-1635. 2267-2276. 